united to the full depth of the abdominal walls, while the lower half closed over outside, but left an open space on the inside, into which the bowels crowded and gave the patient considerable distress. The form of this opening was such as to render any strangulation impossible, and after a few months it became so much diminished in size by cicatricial contractions as to require only the support of a bandage inclosing a pad, to give her perfect comfort and safety.

\title{
RUPTURE OF THE RECTUM, CAUSED BY A FALL UPON THE ABDOMEN.
}

BY FRANK WELLS, M. D.,

Consulting Physician to the Cleveland City Hospital.

A sTrEet fruit-vender, forty years of age, entered the Cleveland City Hospital on the morning of February 24, 1876, under the following circumstances. About eleven o'clock on the preceding night, in stepping from a platform three and a half feet high, in his little fruit shanty, he stumbled, struck the ground with the soles of his feet, lurched forward, and fell upon the edge of a box, striking his abdomen midway between the umbilicus and the symphisis pubis. He immediately felt "as though something had given away inside," and experienced also a slight pain in the lower portion of the hypogastrium, shooting downwards towards the perinæum. He remained in his shanty all night, and resumed work the next morning. At ten A. M. the pain had become so intense that he sent for a physician, who found him standing up and groaning. His face was neither pale nor flushed; he did not complain of any thirst; the pulse was 130 and thready. He was immediately given a hypodermic injection of morphia and sent to the hospital.

When admitted, he was to a great extent under the influence of the drug. The pulse was 90 and full, the face anxious but not pale. $\mathrm{He}$ was groaning with pain, referred to the whole surface of the abdomen, which was tender upon pressure, and slightly tympanitic. He was immediately ordered morphia pro re nata, brandy and quinine at frequent intervals, and turpentine stupes to his abdomen. Upon the following morning he passed his urine freely, and had two dejections from the bowels, which were reported to have been natural in consistence, but somewhat dark in color and mixed with considerable mucus. He gradually fell into a state of unconsciousness, the pulse becoming more rapid and feeble until his death, which occurred at noon on Sunday, February 27 th.

Autopsy at two P. M. A quantity of purulent serum was found in the abdominal cavity, and an exudation of a thin, gray membrane agglutinating the intestines and neighboring parts. The most remarka- 
ble discovery, however, was that of a longitudinal laceration, two inches in length, situated in the central portion of the rectum, through which the fæces were extruding. The liver was cirrhotic.

The chief points of interest about this case are that a blow upon the abdomen should have caused a rupture of the rectum so low down, and that with such a serious injury the patient should have been able the next morning to attend to his work. In regard to the first point, I am of the opinion that the rupture would not have taken place had not the rectum been loaded with fæces. At least, in the absence of all knowledge of the condition of the bowels, I assume this to be the case, since otherwise I cannot imagine that the accident would have been possible.

\section{RECENT PROGRESS IN DERMATOLOGY.}

BY JAMES C. WHITE, M. D.

Formation of Epidermis by the Transplanting of Hairs. - Dr. Schweininger ${ }^{1}$ reports successful results in inducing cicatrization by transplanting to granulating surfaces hairs pulled out by the roots. Placed upon ulcers they formed as many centres of new epithelial growth, which spread outwards, coalesced, and produced rapid and complete cicatrization. These islands proceeded without doubt from the cells of the outer root sheath, which is continuous with the epidermal cells of the rete mucosum, so that epithelium is here developed from preëxisting epithelial cells.

Distribution of the Nerves in the Cuticle. - Dr. Ditlevsen contributes ${ }^{2}$ the results of his observations upon the skin of the frog, from which it appears that bundles of nerve fibres ascend directly to the very base of the horny layer, where they subdivide and are distributed to ramify singly among its cells, and to reach even the free outer surface of the skin.

Treatment of Pityriasis Capitis by Solution of Chloral Hydrate. Martineau communicates ${ }^{3}$ to the Société de Therapeutique the results of his treatment of this affection in this way during the last two years. Twenty-five grammes of the chloral are dissolved in five hundred of water, and the solution is applied freely to the scalp by a sponge. The patient feels a slight heat and the skin becomes red, but the reaction lasts but a few moments. The itching becomes less on the first day, and sometimes does not return. A few applications generally suffice, and in fresh cases a complete cure may be thus obtained, while in chronic forms great amelioration always results.

1 Vierteljahresschrift für die praktische Heilkunde. Erster Band. 1876.

2 Centralblatt für die medicinischen Wissenschaften, 1876, No. 10.

8 Gazette des Hospitaux, March 4, 1876. 